\title{
Two-year mortality and functional outcomes in combat-related penetrating brain injury: battlefield through rehabilitation
}

\author{
M. Benjamin Larkin, MD, PharmD, ${ }^{1,2}$ Erin K. M. Graves, MD, MA, ${ }^{1,3}$ Jason H. Boulter, MD, ${ }^{4}$ \\ Nicholas S. Szuflita, MD, MPH, ${ }^{4}$ R. Michael Meyer, MD, ${ }^{5}$ Michael E. Porambo, MD, ${ }^{1,4}$ \\ John J. Delaney, MD, ${ }^{4}$ and Randy S. Bell, MDD,6
}

${ }^{1}$ F. Edward Hébert School of Medicine, Uniformed Services University, Bethesda, Maryland; '2Department of Neurosurgery, Baylor College of Medicine, Houston, Texas; ${ }^{3}$ Department of Neurosurgery, Temple University, Philadelphia, Pennsylvania; ${ }^{4}$ Walter Reed National Military Medical Center, Bethesda, Maryland; ${ }^{5}$ Division of Neurosurgery, University of Washington, Seattle, Washington; and ${ }^{6}$ Division of Neurosurgery, Department of Surgery, Uniformed Services University, Bethesda, Maryland

OBJECTIVE There are limited data concerning the long-term functional outcomes of patients with penetrating brain injury. Reports from civilian cohorts are small because of the high reported mortality rates (as high as 90\%). Data from military populations suggest a better prognosis for penetrating brain injury, but previous reports are hampered by analyses that exclude the point of injury. The purpose of this study was to provide a description of the long-term functional outcomes of those who sustain a combat-related penetrating brain injury (from the initial point of injury to 24 months afterward).

METHODS This study is a retrospective review of cases of penetrating brain injury in patients who presented to the Role 3 Multinational Medical Unit at Kandahar Airfield, Afghanistan, from January 2010 to March 2013. The primary outcome of interest was Glasgow Outcome Scale (GOS) score at 6, 12, and 24 months from date of injury.

RESULTS A total of 908 cases required neurosurgical consultation during the study period, and 80 of these cases involved US service members with penetrating brain injury. The mean admission Glasgow Coma Scale (GCS) score was 8.5 (SD 5.56), and the mean admission Injury Severity Score (ISS) was 26.6 (SD 10.2). The GOS score for the cohort trended toward improvement at each time point (3.6 at 6 months, 3.96 at 24 months, $p>0.05$ ). In subgroup analysis, admission GCS score $\leq 5$, gunshot wound as the injury mechanism, admission ISS $\geq 26$, and brain herniation on admission CT head were all associated with worse GOS scores at all time points. Excluding those who died, functional improvement occurred regardless of admission GCS score $(p<0.05)$. The overall mortality rate for the cohort was $21 \%$. CONCLUSIONS Good functional outcomes were achieved in this population of severe penetrating brain injury in those who survived their initial resuscitation. The mortality rate was lower than observed in civilian cohorts.

https://thejns.org/doi/abs/10.3171/2018.9.FOCUS18359

KEYWORDS ballistics; combat; functional outcomes; Glasgow Outcome Scale; military; neurosurgery; penetrating brain injury

$\mathrm{S}$ EVERE closed and penetrating brain injuries (PBIs) remain considerable clinical and research challenges, and there is a relative paucity of evidence to guide management practices. This is due largely to the fact that the majority of PBI patients seen at civilian trauma cen- ters in the US are victims of gunshot wounds to the head (GSWH) and their prognosis is poor, 2,16,24,27 with overall

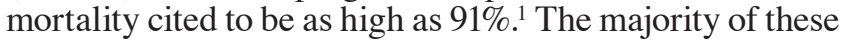
deaths occur at the point of injury or shortly thereafter. Aarabi et al. reported in 2014 that $76 \%$ of 786 patients died

ABBREVIATIONS EVD = external ventricular drain; GCS = Glasgow Coma Scale; GOS = Glasgow Outcome Scale; GSWH = gunshot wound to the head; ICP = intracranial pressure; ISS = Injury Severity Score; KAF = Kandahar Airfield; PBI = penetrating brain injury; WRNMMC = Walter Reed National Military Medical Center. ACCOMPANYING EDITORIAL DOI: 10.3171/2018.9.FOCUS18493.

SUBMITTED July 15, 2018. ACCEPTED September 10, 2018

INCLUDE WHEN CITING DOI: 10.3171/2018.9.FOCUS18359. 
at the point of injury, which is consistent with the $71 \%$ reported by Kaufman et al. in 1986 and the $73 \%$ reported by Siccardi et al. in 1991.,17,34

For patients who sustain PBI and do survive their injuries, little is known about their potential for a functional recovery. In a review of 4 previous studies concerning civilian GSWH, 2,16,24,27 a total of 349 patients were re-stratified on the basis of their admission Glasgow Coma Scale (GCS) and long-term Glasgow Outcome Scale (GOS) scores (with GOS scores $\geq 4$ indicating a good functional outcome). This review found that $66 \%$ had an admission GCS score of 3-5 and 93\% of patients in this group died, with only 2 patients $(0.9 \%)$ ever achieving functional independence, defined by a GOS $\geq 4 .{ }^{5}$ In the remaining onethird of patients with an admission GCS score $\geq 6,60 \%$ eventually achieved functional independence. ${ }^{5}$ In all, $21 \%$ of patients who presented to the emergency department after damage control resuscitation ever achieved functional independence. ${ }^{5}$

In contrast, a 2012 study by Weisbrod et al. of 137 military PBI patients managed at the Walter Reed National Military Medical Center (WRNMMC) reported 5.8\% mortality and $68 \%$ achievement of functional independence (mean GOS 4). ${ }^{35}$ Notably, $32 \%$ of those with an admission GCS score of 3-5 ultimately had a GOS score $\geq 4$. This contrasts markedly with the $<1 \%$ of civilian patients with similar admission GCS scores. ${ }^{5}$ While a superficial analysis might conclude that this represents a significant difference in survivability between military and civilian cohorts, this conclusion cannot be drawn based on available data due to immortal time bias. The study by Weisbrod et al., like many before it, was unable to account for those who died prior to arrival at hospitals within the US and therefore may overestimate the survivability of PBI in that cohort. $3,4,13,28,35$

With this in mind, our purpose in this paper was to characterize the long-term outcomes of those who sustain combat-related PBI by analyzing a cohort of patients from point of injury forward. The following is therefore a retrospective analysis of a cohort of active-duty US military personnel who sustained a PBI in combat and survived to be evaluated by a deployed neurosurgeon and for whom GOS scores could be calculated at 6, 12, and 24 months after injury.

\section{Methods}

\section{Design and Data Collection}

This study is a retrospective review of all cases involving US military members who underwent neurosurgical consultation at the Role 3 Multinational Medical Unit at Kandahar Airfield (KAF) in Afghanistan from January 2010 to March 2013. It was conducted in accordance with a protocol approved by the WRNMMC Institutional Review Board. Patients were identified through the US Army Institute of Surgical Research (USAISR) trauma registry. These results were cross-referenced with the Theater Medical Data Store (TMDS) to exclude patients who had sustained head, neck, or facial trauma that did not violate the calvaria, leaving only those with PBI. Records of admission GCS scores were available for only 64 of the 80 patients. Patients without available admission GCS data were not included in associated analyses utilizing admission GCS scores.

Demographical data were collected including branch of service, mechanism of injury, admission Injury Severity Score (ISS), admission GCS score (determined by a neurosurgeon or trauma surgeon upon patient admission), injury characteristics, and surgical interventions (craniotomy, craniectomy, or intracranial pressure [ICP] monitor/ external ventricular drain [EVD] placement). GOS scores (present for all patients at all time points) were determined at 6,12 , and 24 months postinjury independently by 2 investigators through a review of the medical records that included inpatient and outpatient neurosurgery evaluations at that time. Notes from multiple disciplines within approximately 1 month of each time point were utilized to minimize error in score determination. Any differences in score assignment were resolved by adjudication from a blinded third investigator.

\section{Outcomes and Statistical Analysis}

The primary outcome of interest for the present study was GOS score at 6,12 , and 24 months postinjury. Patients were segregated by mechanism of injury, admission GCS score, admission ISS, and injury characteristics and were evaluated for changes in GOS score as either a continuous or a dichotomized ( $\geq 4$ as "good" and $<4$ as "poor") variable at each time point.

Descriptive statistics were calculated as means with standard deviations or counts with percentages where appropriate. Categorical variables were analyzed with Fisher's exact test, and continuous variables were analyzed with Student's t-test and analyses of variance. Statistical significance was set at $p<0.05$. All statistics were performed with Microsoft Excel 2013.

\section{Results}

\section{Patient Population}

The neurosurgery service at KAF received requests for consultations on 908 cases during the study period. Among them, 156 (17\%) involved US service members for whom follow-up data were available. The remaining consultations involved NATO allied and non-NATO allied military members, enemy combatants, and local civilians. Among the US service members, a total of $80(51 \%)$ were found to have sustained a PBI (Table 1).

All patients were male; their mean age was 24.9 years, and the majority were seriously injured (mean admission GCS score 8.5 [SD 5.56], $\mathrm{n}=64$; mean admission ISS 26.7 [SD 10.2], $\mathrm{n}=80$ ). The most common mechanism of injury was blast-related (73\%). The most common injuries sustained included intraparenchymal hemorrhage, subarachnoid hemorrhage, and subdural hemorrhage. Surgical intervention was undertaken for $47 \%$ of patients, and the overall cohort mortality rate was low at $21 \%$ (17 patients) (34\% in the group presenting with an admission GCS score of 3-5; Table 1). Of the 17 patients who died, 11 presented with an admission GCS score $\leq 5$, and in the remaining 6 cases, no admission GCS score was recorded. All patients in the study cohort who presented with an ad- 
mission GCS score $>6$ survived. No patients were lost to follow-up during the study period.

\section{GOS Scores}

Overall, the cohort demonstrated no significant improvement in GOS scores over the study period (mean 3.58 [SD 1.51] at 6 months, 3.80 [1.56] at 12 months, and 3.96 [1.60] at 24 months, $p=0.29$; Fig. 1). Segregation of patients by admission GCS score demonstrated significantly higher GOS scores at all time points for patients with an admission GCS score $\geq 6$ (mean 4.56 [SD 0.66] vs 2.84 [1.48] at 6 months, 4.75 [0.51] vs 3.16 [1.69] at 12 months, and 4.91 [0.30] vs 3.38 [1.81] at 24 months, $\mathrm{p}<$ 0.01 at all time points) but no difference between GOS scores over time within each admission GCS score group (Fig. 2). Patients who presented with an admission GCS score of 6-15 demonstrated a significant increase in GOS score at 24 months when compared to their GOS score at 6 months (mean 4.91 [SD 0.30] vs 4.56 [0.67], $\mathrm{p}=0.01$ ). Additionally, when patients who died were removed from the admission GCS score 3-5 cohort, there was a significant increase in mean GOS score from 6 to 12 months (3.81 [SD 0.75] vs 4.29 [0.72], respectively, $\mathrm{p}=0.04$ ) and from 6 to 24 months (3.81 [SD 0.75] vs 4.62 [0.59], respectively, $\mathrm{p}<0.01$ ), although there was no significant difference in mean GOS score between 12 and 24 months (4.29 [SD 0.72] vs 4.62 [0.59], respectively, $\mathrm{p}=0.11$ ). Similarly, patients with an admission ISS $\leq 25$ demonstrated higher mean GOS scores at all time points than those with an aISS $\geq 26$ (4.03 [SD 1.20] vs 3.22 [1.64] at 6 months, $\mathrm{p}=$ $0.02 ; 4.29$ [1.18] vs 3.42 [1.73] at 12 months, $\mathrm{p}=0.01$; and 4.51 [1.15] vs 3.53 [1.78] at 24 months, $\mathrm{p}=0.01$ ) with no difference over time within any of the groups (Fig. 3). PBI secondary to blast injury also resulted in a more favorable GOS score at all time points when compared to GSWH (mean 3.91 [SD 1.37] vs 2.68 [1.52] at 6 months, 4.10 [1.37] vs 3.00 [1.77] at 12 months, and 4.28 [1.37] vs 3.14 [1.88] at 24 months, $\mathrm{p}<0.01$ at all time points), again with no significant difference in GOS score over time for either group (Fig. 4).

Of the injury characteristics observed, only herniation at presentation was associated with a significantly worse GOS score at all time points (poor outcome in 93\% at 6 months, $93 \%$ at 12 months, and $87 \%$ at 24 months, $\mathrm{p}<0.01$ at all time points; Table 2). There was no significant association with GOS score for any other injury characteristic.

Interestingly, no difference in mean GOS score at any time point was found between those who underwent surgical intervention and those who did not (3.45 [SD 1.39] vs 3.69 [1.62] at 6 months, $\mathrm{p}=0.47 ; 3.71$ [1.45] vs 3.88 [1.67] at 12 months, $\mathrm{p}=0.63 ; 3.95$ [1.51] vs 3.98 [1.70] at 24 months, $\mathrm{p}=0.94$ ) despite the fact that the average admission GCS score in the group who underwent surgical intervention was lower than that in the group who did not (5.41 [SD 4.22] vs 11.00 [5.31], respectively, $\mathrm{p}<0.01$; Fig. 5).

\section{Discussion}

Penetrating brain injury represents one of the most challenging clinical entities for both civilian and military
TABLE 1. Demographic and clinical characteristics and mortality data for the 80 patients in the study cohort

\begin{tabular}{|c|c|}
\hline Variable & Value \\
\hline Age in years, mean (range) & $24.9(19-40)$ \\
\hline \multicolumn{2}{|l|}{ Service, $\mathrm{n}(\%)$} \\
\hline Army & $49(61 \%)$ \\
\hline Navy & $2(3 \%)$ \\
\hline Air Force & $6(8 \%)$ \\
\hline Marine Corps & $23(29 \%)$ \\
\hline \multicolumn{2}{|l|}{ Mechanism of injury, $n(\%)$} \\
\hline Blast & $58(73 \%)$ \\
\hline GSWH & $22(28 \%)$ \\
\hline Admission GCS score, $n=64$, mean (SD) & $8.5(5.56)$ \\
\hline $6-15$ & $33(52 \%)$ \\
\hline $3-5$ & $31(48 \%)$ \\
\hline Admission ISS, mean (SD) & $26.6(10.2)$ \\
\hline Mild to moderate, ISS $\leq 25, \mathrm{n}(\%)$ & $35(44 \%)$ \\
\hline Severe to critical, ISS $\geq 26, \mathrm{n}(\%)$ & $45(56 \%)$ \\
\hline \multicolumn{2}{|l|}{ Injury characteristics, n (\%) } \\
\hline Epidural hematoma & $5(6 \%)$ \\
\hline Subdural hematoma & $24(30 \%)$ \\
\hline Subarachnoid hemorrhage & $35(44 \%)$ \\
\hline Intraparenchymal hemorrhage & $60(75 \%)$ \\
\hline Intraventricular hemorrhage & $5(6 \%)$ \\
\hline Vascular injury & $7(9 \%)$ \\
\hline Retained fragments & $36(45 \%)$ \\
\hline Herniation & $15(19 \%)$ \\
\hline \multicolumn{2}{|l|}{ Surgical intervention, $\mathrm{n}(\%)$} \\
\hline No intervention & $42(53 \%)$ \\
\hline Intervention & $38(47 \%)$ \\
\hline Craniotomy & $8(11)$ \\
\hline Craniectomy & $28(37)$ \\
\hline ICP monitor/EVD & $30(39)$ \\
\hline \multicolumn{2}{|l|}{ Mortality } \\
\hline At KAF & $13(16 \%)$ \\
\hline After evacuation & $4(5 \%)$ \\
\hline
\end{tabular}

GCS = Glasgow Coma Scale; GSWH = gunshot wound to the head; ISS = Injury Severity Score; KAF = Kandahar Airfield.

neurosurgeons. Since 2003, the conflicts in Iraq and Afghanistan have resulted in the highest number of PBIs for US servicemen and -women since the Vietnam War. Previous studies analyzing outcomes for these patients have suggested that mortality is much lower than in civilian cohorts, and good functional outcomes can be obtained even for those with low admission GCS scores $(<5))^{1,4,17,34,35}$ These studies were hampered by the absence of analysis of data from the point of injury (immortal time bias), and considered outcomes only for those patients who survived to reach definitive care after long air evacuation transport to the continental US. This study was therefore undertaken for 2 reasons: first, to assess whether functional outcomes and mortality differed from what has been reported in prior military studies, and second, to assess whether or 


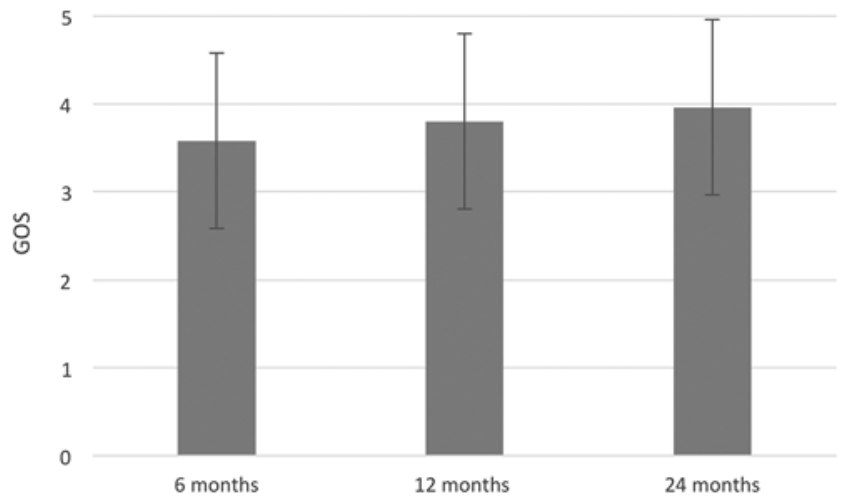

FIG. 1. GOS scores over time for study population.

not outcomes for PBI differ descriptively between military and civilian populations. To our knowledge, this is the first paper analyzing long-term outcomes for patients with PBI in a US military cohort from the point of injury forward.

This study revealed that good functional outcomes were achieved for those who sustained combat-related PBI and survived their initial resuscitation (GOS scores at 6,12 , and 24 months), confirming conclusions from prior studies. ${ }^{4,35}$ The mortality rate in this study, $21 \%$, was higher than that reported in previous military cohorts, but lower than in published civilian studies. $1,4,17,34,35$ This finding is not surprising, and our rate of $21 \%$ is likely a truer estimation of mortality from PBI in these conflicts than previously estimates. Commensurate with prior reports, in our study cohort, explosive devices were the leading cause of PBI. ${ }^{4,22,35}$ This study also revealed an association between the following factors and overall worse outcome at all time points: admission GCS score $\leq 5$, admission ISS $\geq 26$, brain herniation on admission CT scan of the head, and gunshot wound as the mechanism of injury.
The association between low admission GCS score and worse early outcome has been well described for civilian cohorts. ${ }^{2,16,24,27}$ In these civilian cohorts, where gunshot wound was the predominant mechanism of PBI, over $90 \%$ of patients who presented with an admission GCS score of 3-5 died, with almost none achieving a good functional outcome. In contrast, in the current study, half of the patients presented with an admission GCS score of $3-5$, and roughly one-third of these patients died and two-thirds survived to achieve good functional recovery. Explanations for the improved survivability may include the use of protective gear (helmets, body armor) in the military population and the predominant mechanism of injury in the military population (blast; see below). ${ }^{6,7,19,21,31-33}$ It is also conceivable that the reported admission GCS score in this military population may be artificially lower than the actual admission GCS score as a result of ongoing sedation/neuromuscular blockade from field resuscitation and/ or a poor understanding of the GCS by reporting field personnel. ${ }^{18,29}$ In our view, this also complicates estimation of field GCS scores in civilian settings. The fact that those patients in our cohort who did survive showed an upward mobility in their GOS scores is consistent with previous studies that show only a weak correlation between admission GCS scores and long-term outcome and may be explained by the above considerations..$^{10,11,15,20,26}$ All that said, the fact that so many patients with admission GCS scores $\leq 5$ had good functional outcomes in this cohort should caution forward deployed neurosurgeons to consider intervention, rather than expectant management, in this population. Further study is necessary to elucidate the granular differences in this unique population.

It is interesting to note that those patients in this cohort who presented with PBI secondary to gunshot wound had worse functional outcomes at all time points than those who suffered a blast PBI. The mortality rate for those who presented with GSWH was $41 \%$ (9/22 patients) compared

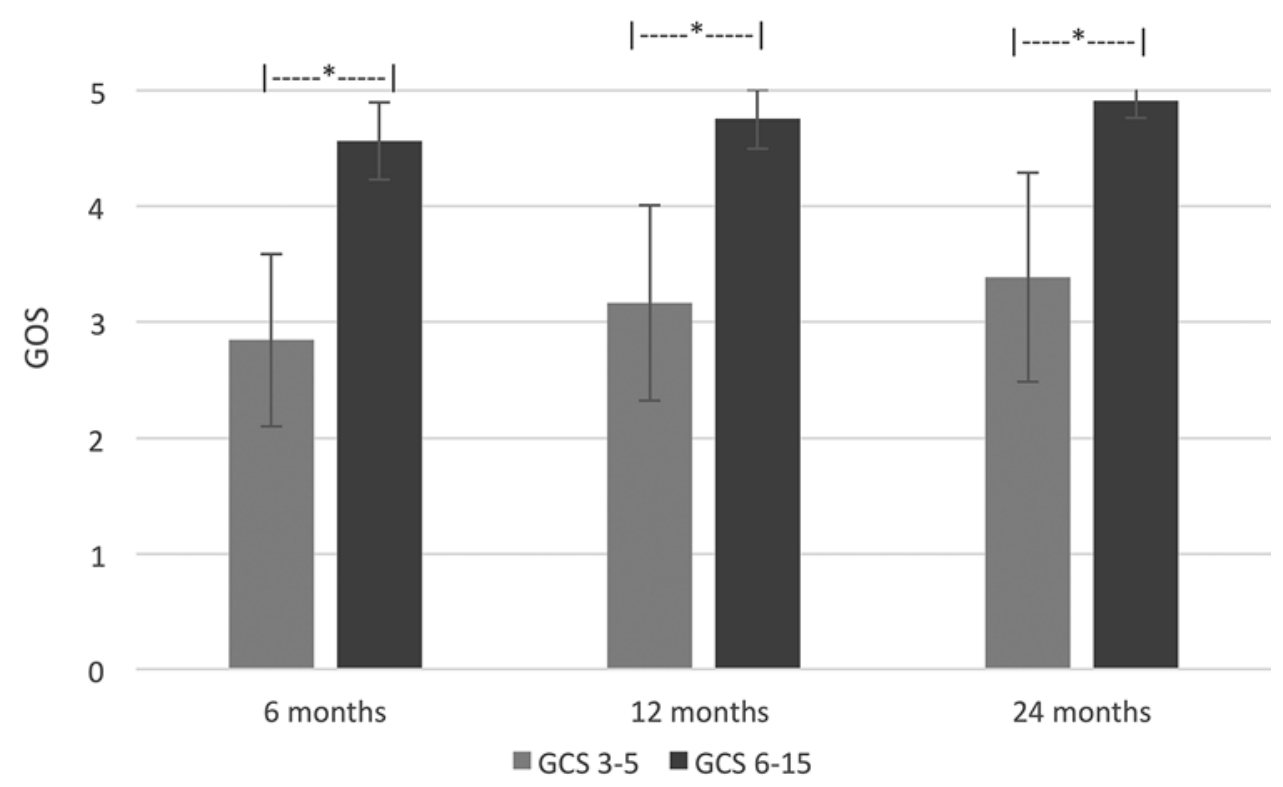

FIG. 2. Mean GOS scores over time stratified by admission GCS score. Error bars indicate SDs. ${ }^{*} p<0.05$. 


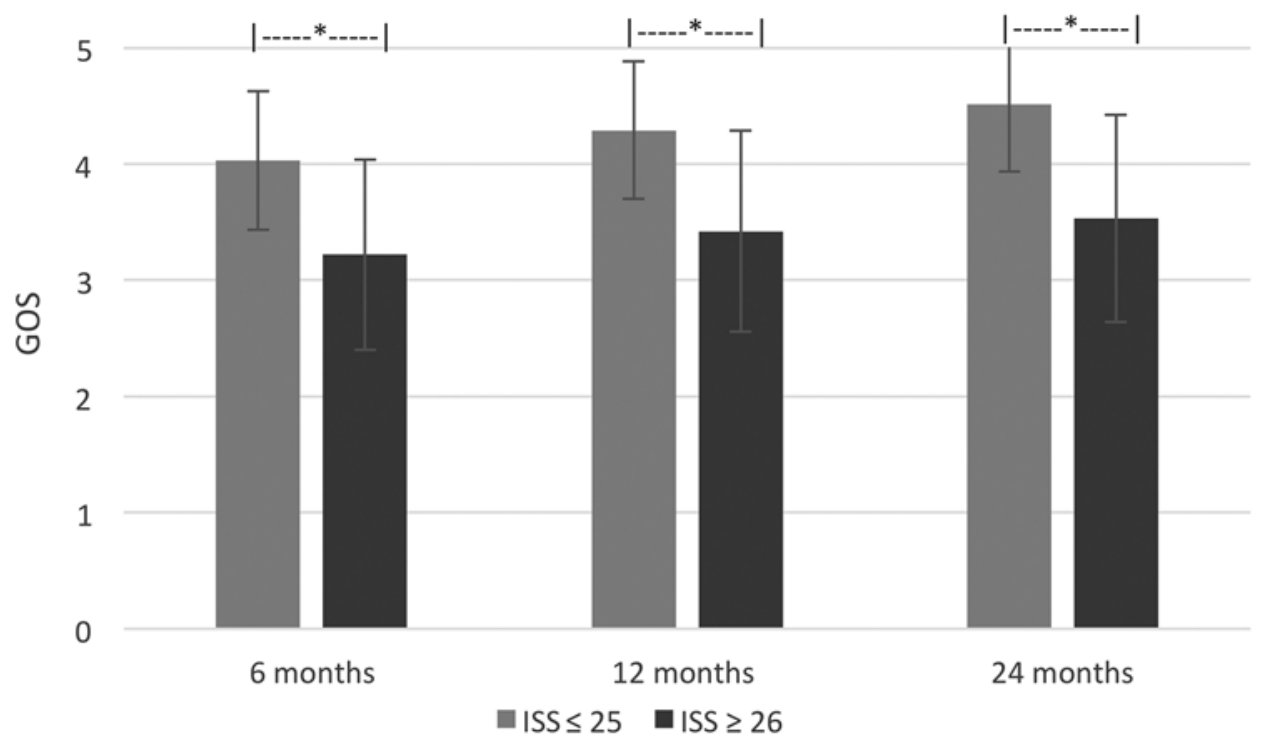

FIG. 3. Mean GOS scores over time stratified by admission ISS. Error bars indicate SDs. * $p<0.05$.

to $14 \%$ for those who suffered blast PBI; this GSWH mortality rate more closely mirrors the civilian experience. This observation is interesting when considering the complexity (blast overpressure, polytrauma) of blast-related injuries, especially in this setting where those with admission ISS $\geq 26$ had worse functional outcomes. , $^{8,14,23,25,31}$

Nearly half of the patients in this study required some form of surgical intervention. As expected, those who required surgery presented with lower admission GCS scores in comparison to those who did not require surgery. Interestingly, analysis revealed that long-term functional outcomes did not differ between those requiring surgery and those who did not. While this finding was surprising and may be a reflection of the predominant mechanism of injury (blast vs GSWH) and/or the tendency for early and aggressive intervention by military surgeons, the small size of the population precludes solid relational conclusions. ${ }^{5,12,30,35}$

\section{Limitations}

The results of this study, while suggestive of trends for all US military personnel, apply only to those patients included in this cohort. As with many previous studies concerning trauma, all of the patients in this cohort were male. The results may therefore not apply to the active-duty female population.

Despite the intention of limiting immortal time bias, there remains some element in this study. Only those patients who were evacuated to the Multinational Medi-

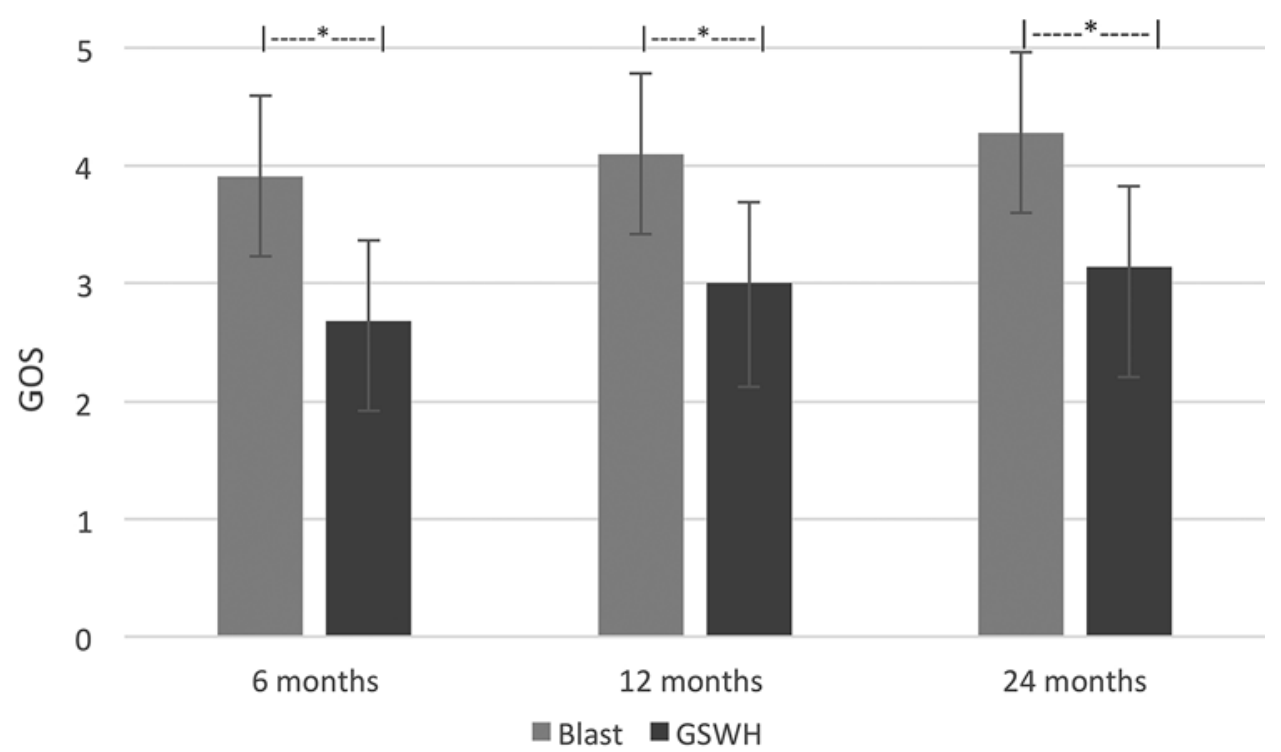

FIG. 4. Mean GOS scores over time stratified by mechanism of injury. Error bars indicate SDs. ${ }^{*} p<0.05$. 
TABLE 2. Injury characteristics and GOS scores for the 80 patients in the study cohort

\begin{tabular}{|c|c|c|c|c|c|c|c|c|c|}
\hline & \multicolumn{3}{|c|}{ GOS at 6 Months } & \multicolumn{3}{|c|}{ GOS at 1 Year } & \multicolumn{3}{|c|}{ GOS at 2 Years } \\
\hline & Good & Poor & $p$ Value* & Good & Poor & p Value* & Good & Poor & p Value* \\
\hline Total & $51(64 \%)$ & $29(36 \%)$ & & $59(74 \%)$ & $21(26 \%)$ & & $62(78 \%)$ & $18(23 \%)$ & \\
\hline \multicolumn{10}{|l|}{ Injury characteristics } \\
\hline Epidural hematoma & $2(40 \%)$ & $3(60 \%)$ & 0.35 & $4(80 \%)$ & $1(20 \%)$ & $>0.99$ & $4(80 \%)$ & $1(20 \%)$ & $>0.99$ \\
\hline Subdural hematoma & $15(63 \%)$ & $9(38 \%)$ & $>0.99$ & $19(79 \%)$ & $5(21 \%)$ & 0.58 & $21(88 \%)$ & $3(13 \%)$ & 0.24 \\
\hline Subarachnoid hemorrhage & $20(57 \%)$ & $15(43 \%)$ & 0.35 & $27(77 \%)$ & $8(23 \%)$ & 0.61 & $29(83 \%)$ & $6(17 \%)$ & 0.42 \\
\hline Intraparenchymal hemorrhage & $35(58 \%)$ & $25(42 \%)$ & 0.11 & $42(70 \%)$ & $18(30 \%)$ & 0.25 & $45(75 \%)$ & $15(25 \%)$ & 0.54 \\
\hline Intraventricular hemorrhage & $3(60 \%)$ & $2(40 \%)$ & $>0.99$ & $5(100 \%)$ & 0 & 0.32 & $5(100 \%)$ & 0 & 0.58 \\
\hline Vascular injury & $4(57 \%)$ & $3(43 \%)$ & 0.70 & $4(57 \%)$ & $3(43 \%)$ & 0.37 & $4(57 \%)$ & $3(43 \%)$ & 0.19 \\
\hline Retained fragments & $20(56 \%)$ & $16(44 \%)$ & 0.24 & $25(69 \%)$ & $11(31 \%)$ & 0.45 & $27(75 \%)$ & $9(25 \%)$ & 0.79 \\
\hline Herniation & $1(7 \%)$ & $14(93 \%)$ & $<0.001$ & $1(7 \%)$ & $14(93 \%)$ & $<0.001$ & $2(13 \%)$ & $13(87 \%)$ & $<0.001$ \\
\hline
\end{tabular}

Data are $\mathrm{n}(\%)$.

*Fisher's exact test.

cal Unit at KAF and were evaluated by military medical personnel were included in this study. Those individuals killed in action in the applicable area of operations during this timeframe were not included in this study. As such, the mortality rate associated with PBI in US military personnel may be higher than that reflected in this study.

The authors acknowledge that the efficacy of GOS score determination is known to decline from structured patient evaluations to telephone and further correspondence interviews. However, because of the retrospective nature of this study, and to avoid recall bias, the authors felt that GOS score determination from review of the electronic health record was more reliable than the patient's recollection of historical functional status.

Lastly, CT scans obtained in theater follow the patient to the medical treatment facilities that later care for them, which may or may not have been WRNMMC in the 80 cases included in this study. As a result, at the time of data collection, only the radiological reports were available for review.

\section{Conclusions}

Long-term functional outcomes in the setting of PBI were good for those who survived to evaluation and treatment at the Role 3 Multinational Medical Unit in Kandahar, Afghanistan. Those who presented with lower admission GCS score, higher ISS, gunshot wound as the mechanism of PBI, and herniation on CT had worse functional outcomes at all time points. Two-thirds of the patients in this study with admission GCS scores $\leq 5$ survived to achieve good functional outcomes. Overall, mortality from PBI in this study was higher than that reported in prior military cohort studies and lower than that reported in studies of civilian populations.

\section{Acknowledgments}

We thank the 17 servicemen in our cohort who gave their lives, as well as the many thousands of other servicemen and -women who have died in the service of the United States of America, and all of their families for their sacrifices. We also

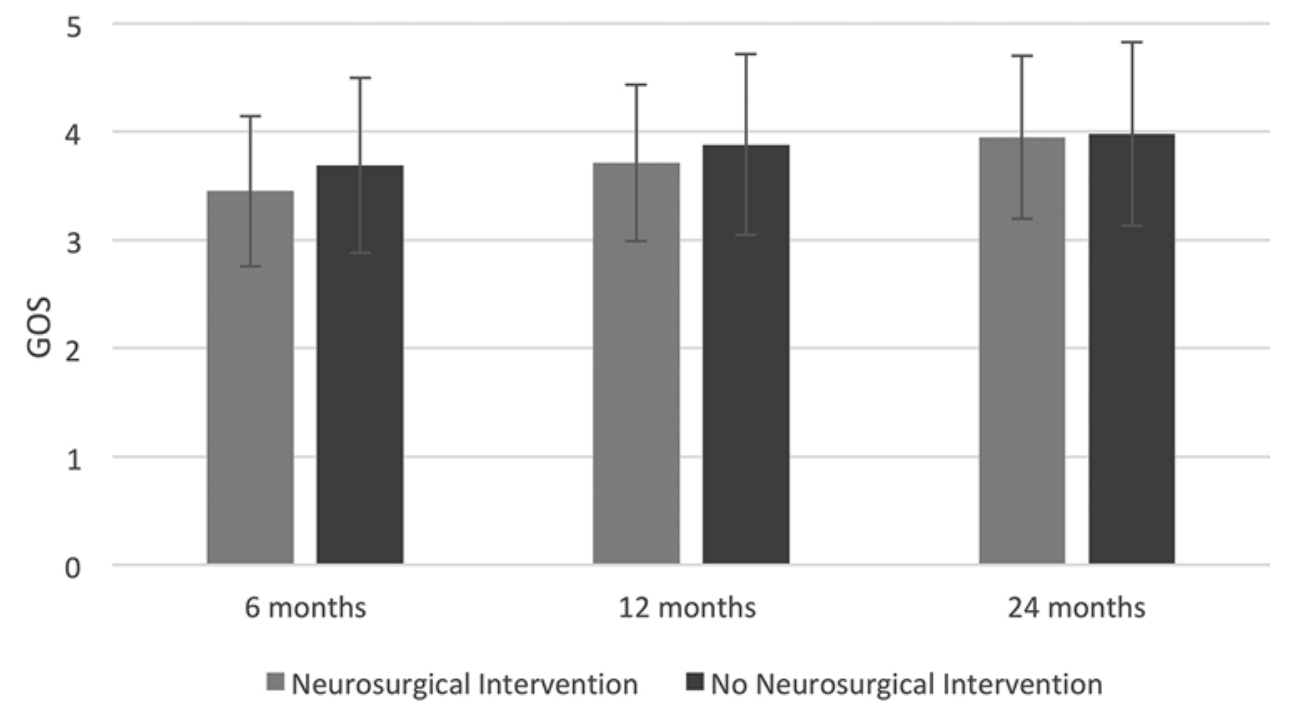

FIG. 5. Mean GOS scores over time stratified by presence or absence of neurosurgical intervention. Error bars indicate SDs. 
thank those neurosurgeons who served at Kandahar Airfield, Afghanistan, during this violent time period. Finally, we thank the other physicians, nurses, combat medics and corpsmen, technicians, and other medical professionals who cared for our patients at all levels of care, including on the battlefield, in the military field hospitals of Afghanistan, at Landstuhl Regional Medical Center in Germany, at military hospitals in the United States, and aboard the aircrafts transporting them.

\section{References}

1. Aarabi B, Tofighi B, Kufera JA, Hadley J, Ahn ES, Cooper C, et al: Predictors of outcome in civilian gunshot wounds to the head. J Neurosurg 120:1138-1146, 2014

2. Aldrich EF, Eisenberg HM, Saydjari C, Foulkes MA, Jane JA, Marshall LF, et al: Predictors of mortality in severely head-injured patients with civilian gunshot wounds: a report from the NIH Traumatic Coma Data Bank. Surg Neurol 38:418-423, 1992

3. Bell RS, Mossop CM, Dirks MS, Stephens FL, Mulligan L, Ecker R, et al: Early decompressive craniectomy for severe penetrating and closed head injury during wartime. Neurosurg Focus 28(5):E1, 2010

4. Bell RS, Vo AH, Neal CJ, Tigno J, Roberts R, Mossop C, et al: Military traumatic brain and spinal column injury: a 5 -year study of the impact blast and other military grade weaponry on the central nervous system. J Trauma 66 (4 Suppl):S104-S111, 2009

5. Carey ME: Bullet wounds to the brain among civilians, in Winn RH, Youmans JR (eds): Youmans Neurological Surgery, ed 5. Philadelphia: WB Saunders, 2004, Vol 4, pp 5223-5242

6. Carey ME, Herz M, Corner B, McEntire J, Malabarba D, Paquette $\mathrm{S}$, et al: Ballistic helmets and aspects of their design. Neurosurgery 47:678-689, 2000

7. Carey ME, Sacco W, Merkler J: An analysis of fatal and nonfatal head wounds incurred during combat in Vietnam by U.S. forces. Acta Chir Scand Suppl 508:351-356, 1982

8. Cernak I: Preclinical models of blast TBI, in Proceedings of the 26th Annual National Neurotrauma Symposium. Gainesville, FL: National Neurotrauma Society, 2008 (Abstract) (http://www.dtic.mil/dtic/tr/fulltext/u2/a640066.pdf) [Accessed October 3, 2018]

9. Cernak I, Savic J, Ignjatovic D, Jevtic M: Blast injury from explosive munitions. J Trauma 47:96-104, 1999

10. Demetriades D, Kuncir E, Murray J, Velmahos GC, Rhee P, Chan L: Mortality prediction of head Abbreviated Injury Score and Glasgow Coma Scale: analysis of 7,764 head injuries. J Am Coll Surg 199:216-222, 2004

11. Dikmen SS, Machamer JE, Powell JM, Temkin NR: Outcome 3 to 5 years after moderate to severe traumatic brain injury. Arch Phys Med Rehabil 84:1449-1457, 2003

12. DuBose JJ, Barmparas G, Inaba K, Stein DM, Scalea T, Cancio LC, et al: Isolated severe traumatic brain injuries sustained during combat operations: demographics, mortality outcomes, and lessons to be learned from contrasts to civilian counterparts. J Trauma 70:11-18, 2011

13. Ecker RD, Mulligan LP, Dirks M, Bell RS, Severson MA, Howard RS, et al: Outcomes of 33 patients from the wars in Iraq and Afghanistan undergoing bilateral or bicompartmental craniectomy. J Neurosurg 115:124-129, 2011

14. Ecklund J: Surgical decompression in penetrating TBI, in Proceedings of the 26th Annual National Neurotrauma Symposium. Gainesville, FL: National Neurotrauma Society, 2008 (Abstract) (http://www.dtic.mil/dtic/tr/fulltext/u2/ a640066.pdf) [Accessed October 3, 2018]

15. Foreman BP, Caesar RR, Parks J, Madden C, Gentilello LM, Shafi $\mathrm{S}$, et al: Usefulness of the abbreviated injury score and the injury severity score in comparison to the Glasgow Coma
Scale in predicting outcome after traumatic brain injury. $\mathbf{J}$ Trauma 62:946-950, 2007

16. Grahm TW, Williams FCJ Jr, Harrington T, Spetzler RF: Civilian gunshot wounds to the head: a prospective study. Neurosurgery 27:696-700, 1990

17. Kaufman HH, Makela ME, Lee KF, Haid RW Jr, Gildenberg PL: Gunshot wounds to the head: a perspective. Neurosurgery 18:689-695, 1986

18. Knuth T, Letarte PB, Ling G, Moores LE, Rhee P, Tauber D, et al: Guidelines for Field Management of Combat-Related Head Trauma. New York: Brain Trauma Foundation, 2005

19. Kulkarni SG, Gao XL, Horner SE, Zheng JQ, David NV: Ballistic helmets - their design, materials, and performance against traumatic brain injury. Compos Struct 101:313-331, 2013

20. Lannoo E, Van Rietvelde F, Colardyn F, Lemmerling M, Vandekerckhove T, Jannes C, et al: Early predictors of mortality and morbidity after severe closed head injury. J Neurotrauma 17:403-414, 2000

21. Lenhart MK, Nessen S, Lounsbury D, Hetz S: War Surgery in Afghanistan and Iraq: A Series of Cases, 2003-2007. Falls Church, VA: Office of the Surgeon General, Department of the Army, 2008

22. Lenhart MK, Savitsky E, Eastridge B: Combat Casualty Care: Lessons Learned from OEF and OIF. Falls Church, VA: Office of the Surgeon General, Department of the Army, 2012

23. Levi L, Fensod M: Long-term outcome after craniocerebral missile wounds: recent military experience, in Aarabi B, Kaufman H (eds): Missile Wounds of the Head and Neck. Stuttgart: Thieme, 1999, pp 411-421

24. Levi L, Linn S, Feinsod M: Penetrating craniocerebral injuries in civilians. Br J Neurosurg 5:241-247, 1991

25. Ling G: Traumatic brain injury and the global war on terror, in Proceedings of the 26th Annual National Neurotrauma Symposium. Gainesville, FL: National Neurotrauma Society, 2008 (Abstract) (http://www.dtic.mil/dtic/tr/fulltext/u2/ a640066.pdf) [Accessed October 3, 2018]

26. Marshall LF, Gautille T, Klauber MR, Eisenberg HM, Jane JA, Luerssen TG, et al: The outcome of severe closed head injury. J Neurosurg 75 Suppl:S28-S36, 1991

27. Nagib MG, Rockswold GL, Sherman RS, Lagaard MW: Civilian gunshot wounds to the brain: prognosis and management. Neurosurgery 18:533-537, 1986

28. Neal C, Bell R, Cardoso M, Moquin R, Ecklund J: 724 Injury patterns from Operation Iraqi Freedom seen at Walter Reed Army Medical Center and National Naval Medical Center. Neurosurgery 55:460, 2004 (Abstract)

29. Riechers RG II, Ramage A, Brown W, Kalehua A, Rhee P, Ecklund JM, et al: Physician knowledge of the Glasgow Coma Scale. J Neurotrauma 22:1327-1334, 2005

30. Rosenfeld JV, Bell RS, Armonda R: Current concepts in penetrating and blast injury to the central nervous system. World J Surg 39:1352-1362, 2015

31. Rosenfeld JV, McFarlane AC, Bragge P, Armonda RA, Grimes JB, Ling GS: Blast-related traumatic brain injury. Lancet Neurol 12:882-893, 2013

32. Sarron JC, Dannawi M, Faure A, Caillou JP, Da Cunha J, Robert R: Dynamic effects of a $9 \mathrm{~mm}$ missile on cadaveric skull protected by aramid, polyethylene or aluminum plate: an experimental study. J Trauma 57:236-243, 2004

33. Selden BS, Goodman JM, Cordell W, Rodman GH Jr, Schnitzer PG: Outcome of self-inflicted gunshot wounds of the brain. Ann Emerg Med 17:247-253, 1988

34. Siccardi D, Cavaliere R, Pau A, Lubinu F, Turtas S, Viale GL: Penetrating craniocerebral missile injuries in civilians: a retrospective analysis of 314 cases. Surg Neurol 35:455-460, 1991 
35. Weisbrod AB, Rodriguez C, Bell R, Neal C, Armonda R, Dorlac W, et al: Long-term outcomes of combat casualties sustaining penetrating traumatic brain injury. J Trauma Acute Care Surg 73:1525-1530, 2012

\section{Disclaimer}

The opinions expressed herein are those of the author(s) and are not representative of those of the Uniformed Services University (USU), the Department of Defense (DOD), or the United States Army or Navy.

\section{Disclosures}

The authors report no conflict of interest concerning the materials or methods used in this study or the findings specified in this paper.

\section{Author Contributions}

Conception and design: Larkin, Szuflita, Meyer. Acquisition of data: Larkin, Szuflita, Meyer, Porambo, Delaney. Analysis and interpretation of data: Larkin, Graves, Boulter, Szuflita. Drafting the article: Larkin, Graves, Boulter, Meyer. Critically revising the article: Larkin, Graves, Boulter, Szuflita, Meyer, Porambo, Bell. Reviewed submitted version of manuscript: all authors. Statistical analysis: Boulter, Szuflita. Administrative/technical/material support: Larkin, Meyer, Bell. Study supervision: Bell.

\section{Correspondence}

M. Benjamin Larkin: Baylor College of Medicine, Houston, TX. michael.b.larkin3.mil@mail.mil. 